\title{
The anti-leishmanial drug miltefosine causes insulin resistance in skeletal muscle cells in vitro
}

Received: 8 December 2005 / Accepted: 14 January 2006 / Published online: 3 May 2006

(C) Springer-Verlag 2006

\begin{abstract}
Aims/hypothesis: Miltefosine, the first oral anti-leishmanial drug, is reported to inhibit phosphatidylinositol 3-kinase (PI3K)/Akt activity in carcinoma cell lines. Inhibition of the PI3K/Akt pathway is known to result in insulin resistance. Therefore, we investigated whether miltefosine has any deleterious effect(s) on insulin sensitivity in L6E9 skeletal muscle cells. Materials and methods: L6E9 myotubes were treated with miltefosine and its effect was observed on insulin-signalling proteins such as Akt, PI3K, insulin receptor- $\beta$, IRS-1, $c$-Jun N-terminal kinase, p38 and glycogen synthase kinase $\beta$, as well as on glucose uptake. Results: Miltefosine caused skeletal muscle insulin resistance in vitro by interfering with the insulinsignalling pathway and inhibiting insulin-stimulated glucose uptake. Conclusions/interpretation: Miltefosine may contribute to the risk of type 2 diabetes and needs further clinical exploration.
\end{abstract}

Keywords Insulin resistance $\cdot$ Miltefosine $\cdot$ Skeletal muscle Type 2 diabetes

\footnotetext{
Abbreviations 2-DOG: 2-deoxyglucose - ERK: extracellular signal-regulated kinase - GSK-3 $\beta$ : glycogen synthase kinase $3 \beta \cdot$ IR: insulin receptor - JNK: c-Jun N-terminal kinase $\cdot$ MAPK: mitogen-activated protein kinase - PI3K: phosphatidylinositol 3-kinase ·

$\mathrm{PKB}$ : protein kinase $\mathrm{B}$
}

\section{Introduction}

Miltefosine, a synthetic membrane-permeable alkyl-lysophospholipid, initially developed as an anti-tumour agent and registered as an oral anti-leishmanial drug has shown a broad range of clinical applications [1]. Topical application of miltefosine has been shown to be an effective therapy for cutaneous metastases or skin metastases of breast cancer [2]. It has shown remarkable activity against leishmaniasis and offers great promises in the treatment of parasitic infections including those caused by Leishmania spp. or Trypanosoma spp. [1, 3, 4]. Although no consensus has emerged regarding the mode of action of miltefosine in cancer cells or in parasites, several likely intracellular targets related to signal transduction and lipid biosynthesis have been identified $[1,5]$. Using A431 and HeLa cell lines, it has been reported that miltefosine inhibits the phosphatidylinositol 3-kinase (PI3K)-Akt/protein kinase B (PKB) pathway [5]. Since PI3K and Akt/PKB are considered to be the central mediators of insulin signalling [6], it can be speculated that inhibition of the PI3K-Akt/ PKB pathway in skeletal muscle may inhibit insulinsignalling pathways or promote the accumulation of molecules capable of inhibiting insulin action. This prompted us to hypothesise that miltefosine treatment might result in a condition of insulin resistance. Therefore, the aim of this study was to investigate the effect(s) of miltefosine on insulin-stimulated glucose uptake and putative mediators of insulin action (insulin-signalling proteins) in L6E9 skeletal muscle cells in vitro.

\section{Materials and methods}

Materials

Miltefosine was obtained from Cayman Chemicals (Ann Arbor, MI, USA). DMEM was from Gibco BRL (Carlsbad, CA, USA). FCS was from Biological Industries (Kibbutz Beit Haemek, Israel). All the antibodies were from Cell

Signaling Technology (Beverly, MA, USA). All other
Signal Transduction Research Laboratory,

Department of Biotechnology,

National Institute of Pharmaceutical

Education and Research (NIPER),

Sector 67, S.A.S. Nagar,

Punjab 160062, India

e-mail: csdey@niper.ac.in

Tel.: +91-172214682

Fax: +91-172214682 
reagents, unless attributed explicitly, were from Sigma Chemical Company (St Louis, MO, USA). All plastic-ware was from Tarsons (Kolkata, India).

\section{Cell culture and treatment}

The L6E9 rat skeletal muscle cell line was cultured as described previously [7]. Differentiated myotubes were serumstarved for $6 \mathrm{~h}$, treated with or without miltefosine and then stimulated with or without $100 \mathrm{nmol} / \mathrm{l}$ insulin for $10 \mathrm{~min}$.

a
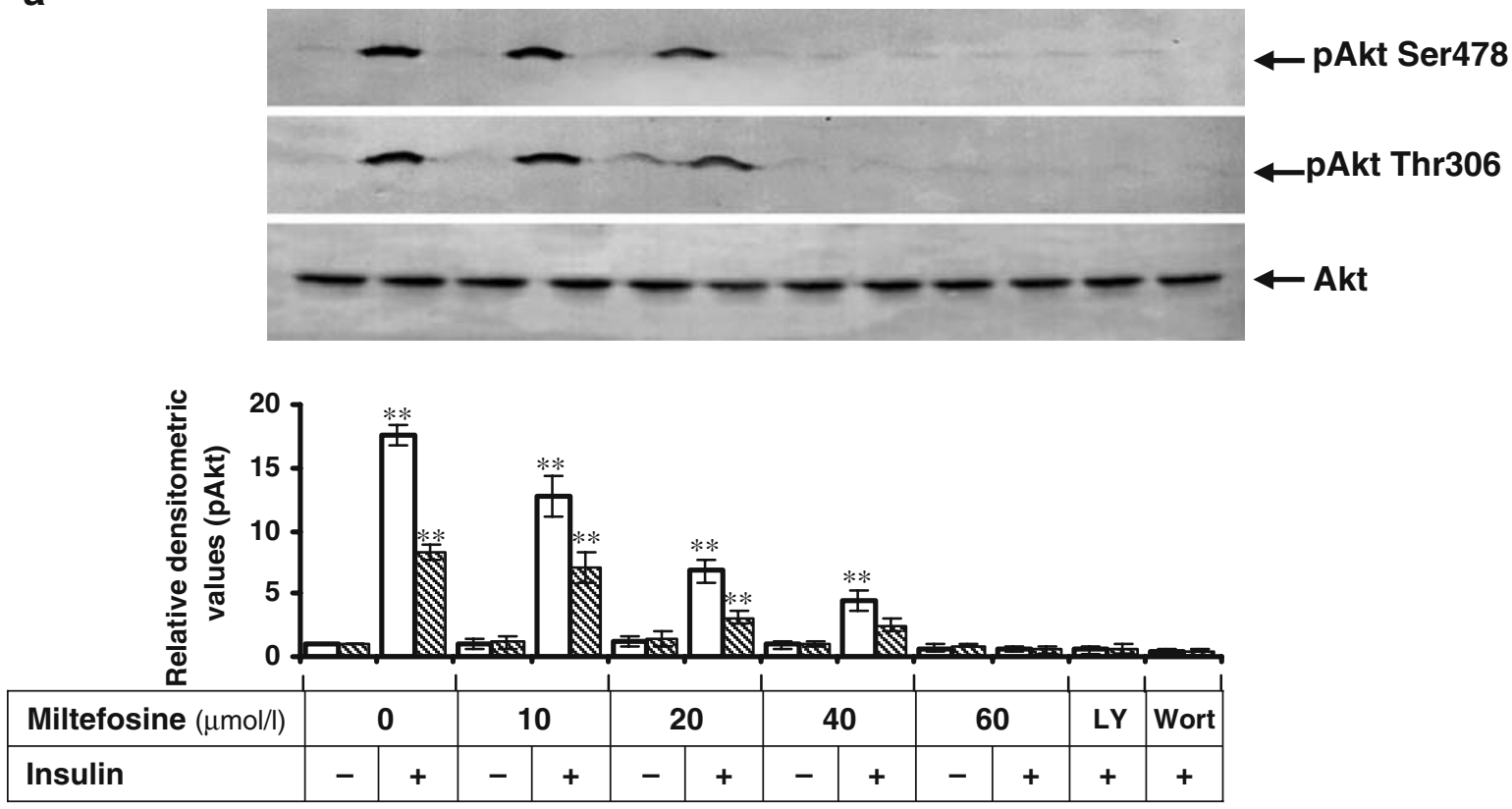

b
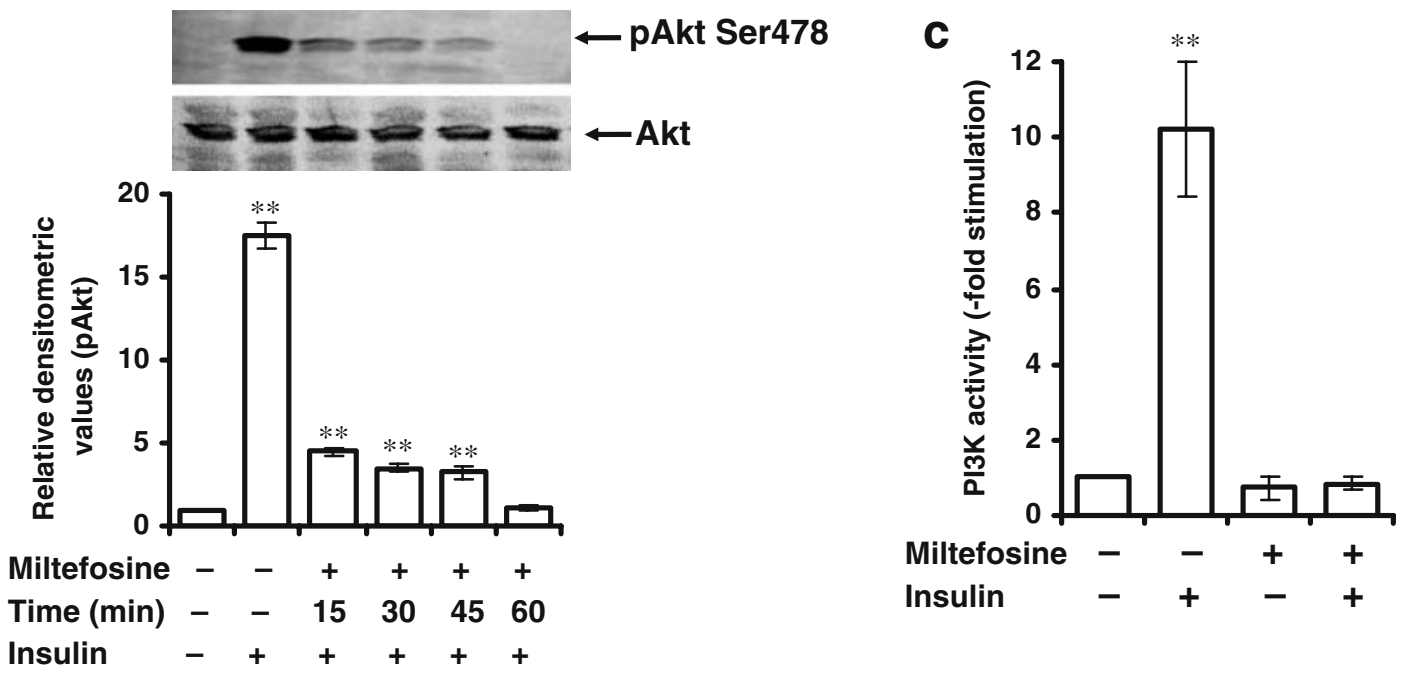

Fig. 1 Effects of miltefosine on the insulin-stimulated activation of Akt/PKB and PI3K. a Differentiated L6E9 cells were pretreated with or without different concentrations of miltefosine $(10,20,40$ or $60 \mu \mathrm{mol} / \mathrm{l})$ and with or without insulin stimulation $(100 \mathrm{nmol} / \mathrm{l}$ for $10 \mathrm{~min}$ ), or $10 \mu \mathrm{mol} / 1 \mathrm{LY} 294002(L Y)$ or $200 \mathrm{nmol} / 1$ wortmannin (Wort) for $30 \mathrm{~min}$ with insulin stimulation, and the phosphorylation of Akt/PKB (Ser478 or Thr306) was measured by Western immunobloting. The bar graph indicates relative densitometric values of the Western blots of phosphorylated Akt $(p A k t)$. Open bars, Ser478; hatched bars, Thr306. b The effect of treatment with $40 \mu \mathrm{mol} / 1$ miltefosine for different time periods $(15,30,45$ or $60 \mathrm{~min}$ ) on insulin-stimulated phosphorylation of Akt (Ser478) was measured by Western immunobloting. The bar graph indicates relative densitometric values of the Western blots of pAkt. c The effect of $40 \mu \mathrm{mol} / 1$ miltefosine treatment for $60 \mathrm{~min}$ with or without insulin stimulation $(100 \mathrm{nmol} / 1$ for $10 \mathrm{~min})$ on activation of IRS-1associated PI3K. Values are means \pm SEM from three independent experiments. ${ }^{* *} p<0.01$ 
Cell lysis, immunoprecepitation and western immunobloting These methods were performed as described previously [8].

PI3K assay IRS-1-associated PI3K activity was measured using a PI3K ELISA kit, as per the manufacturer's (Echelon Biosciences, Salt Lake City, UT, USA) instructions. Briefly, cell lysates $(500 \mu \mathrm{g})$ were immunoprecipitated with anti-IRS-1 antibody and incubated with phosphatidylinosoitol (PI) $(4,5) \mathrm{P}_{2}$ substrate. The reaction was stopped by adding $2.5 \mu 1100 \mathrm{mmol} / \mathrm{l}$ EDTA to each sample and incubated with $50 \mu \mathrm{PI}(3,4,5) \mathrm{P}_{3}$ for $2 \mathrm{~h}$ at $37^{\circ} \mathrm{C}$ in the dark in a detection plate. The plate was washed three times with $\mathrm{NaCl} 150 \mathrm{mmol} / \mathrm{l}$, Tris $10 \mathrm{mmol} / \mathrm{l}$ (pH 7.5), with $0.05 \% \mathrm{v} / \mathrm{v}$ Tween-20, and further incubated for $1 \mathrm{~h}$ with $100 \mu \mathrm{l}$ secondary detection solution. Colour was developed by adding $100 \mu \mathrm{l}$ tetramethylbenzidine solution and stopped by adding $100 \mu \mathrm{l} 0.5 \mathrm{~mol} / 1 \mathrm{H}_{2} \mathrm{SO}_{4}$. Absorbance was recorded at $450 \mathrm{~nm}$ and the enzyme activity was calculated from a standard curve generated according to the manufacturer's instructions.

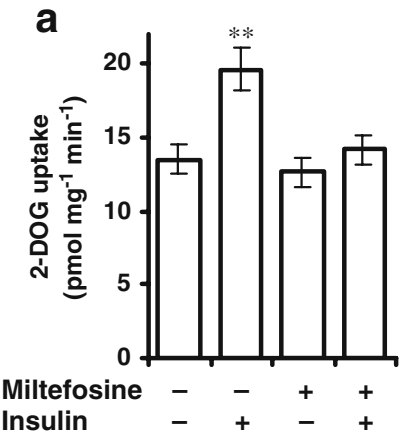

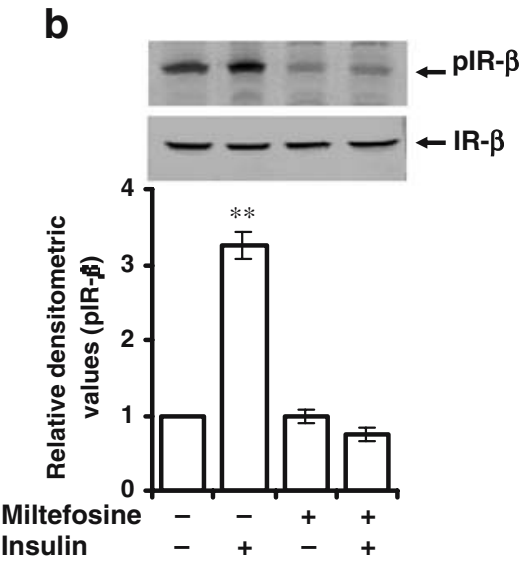

e

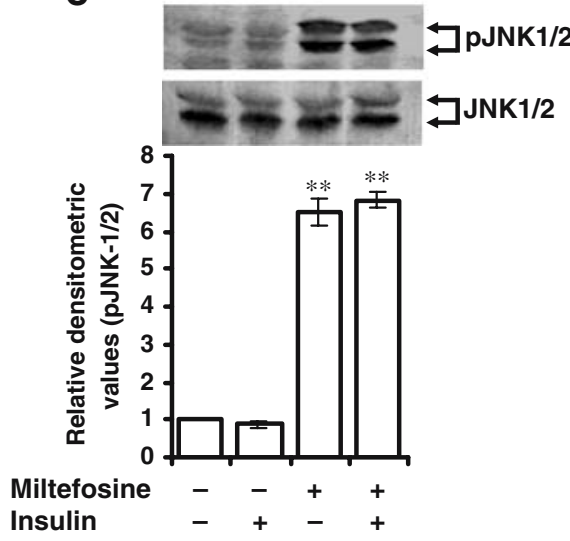

C

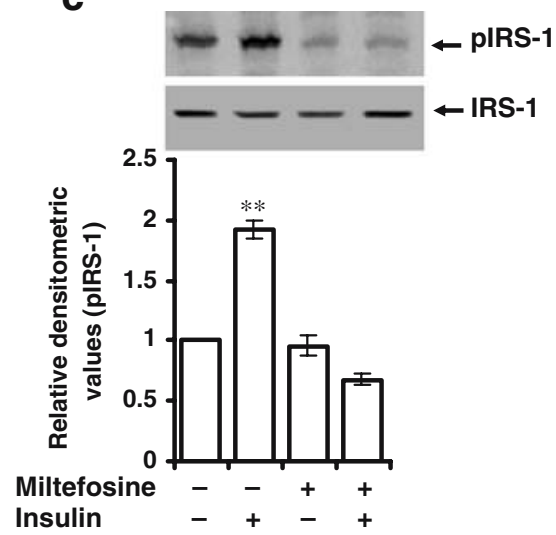

f

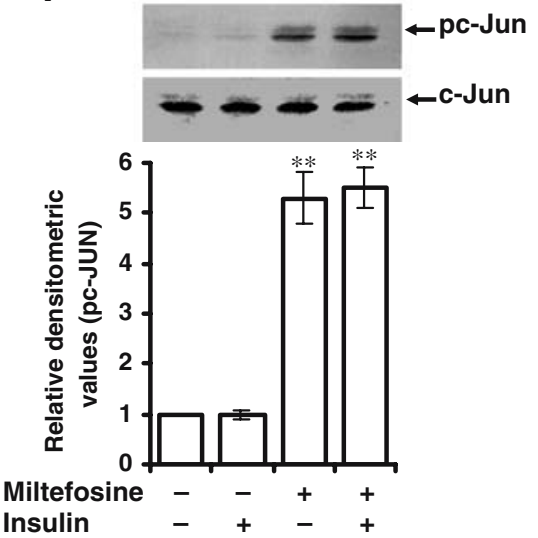

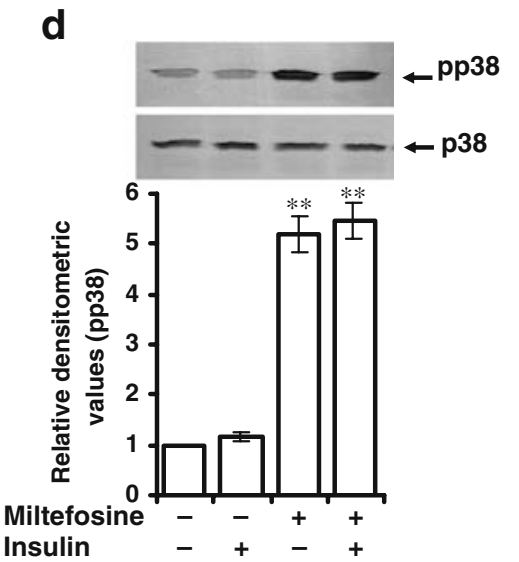

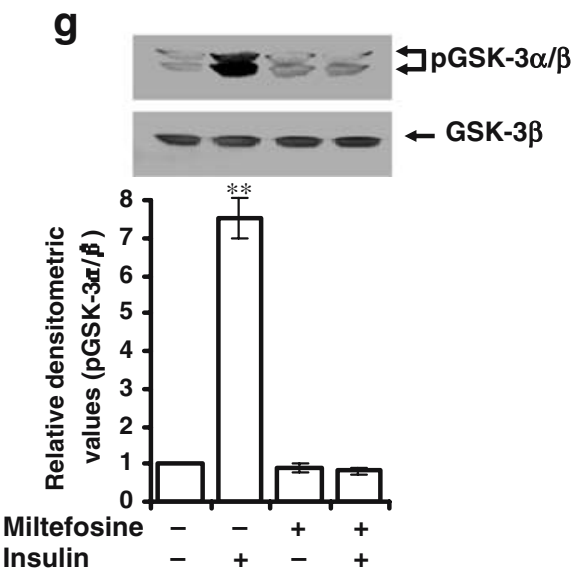

Fig. 2 Effects of miltefosine on 2-DOG uptake a and on insulinsignalling proteins. Differentiated L6E9 cells were pretreated with or without $40 \mu \mathrm{mol} / 1 \mathrm{miltefosine}$ for $60 \mathrm{~min}$, with or without insulin stimulation (100 nmol/l for $10 \mathrm{~min})$. Activation of IR- $\beta$ (b), IRS-1 (c), p38 (d), JNK1/2 (e), c-Jun (f) and GSK-3 $\alpha / \beta$ (g) was measured as their phosphorylated $(p)$ products. Experiments were repeated three times and representative blots are shown. Values are means \pm SEM. $* * p<0.01$ 
Glucose uptake assay The 2-deoxyglucose (2-DOG) uptake assay was performed as described previously [8]. Data are presented as picomoles per milligram per minute.

Statistical analysis Data are expressed as means \pm SEM. For comparison of two groups, $p$ values were calculated by the two-tailed unpaired Student's $t$ - test. In all cases $p<0.05$ was considered to be statistically significant.

\section{Results and discussion}

Miltefosine has been reported to inhibit Akt/PKB phosphorylation leading to cell death in A431 and HeLa cell lines [5]. To investigate whether miltefosine causes similar effect(s) in skeletal muscle cells, differentiated L6E9 cells were pretreated with different concentrations of miltefosine for $30 \mathrm{~min}$ and subsequent insulin-stimulated activity was determined by Western immunoblotting. Miltefosine inhibited insulin-stimulated Akt/PKB phosphorylation in a dose-dependent manner with $75 \%$ inhibition at $40 \mu \mathrm{mol} / 1$ and $98 \%$ inhibition at $60 \mu \mathrm{mol} / 1$ (Fig. 1a). No change in Akt/PKB activation was observed when cells were treated with miltefosine alone (Fig. 1a). A time-course study showed up to $95 \%$ inhibition of insulin-stimulated Akt/ PKB phosphorylation when the cells were pretreated with $40 \mu \mathrm{mol} / 1$ miltefosine for $60 \mathrm{~min}$ (Fig. 1b). Phosphorylation was prevented by pretreatment of the cells with the PI3K inhibitors LY294002 $(10 \mu \mathrm{mol} / 1$ for $30 \mathrm{~min})$ or wortmannin $(200 \mathrm{nmol} / 1$ for $30 \mathrm{~min})$, implying that the event was dependent on the PI3K activity (Fig. 1a). Moreover, miltefosine $(40 \mu \mathrm{mol} / 1$ for $60 \mathrm{~min})$ treatment inhibited insulin-stimulated activation of PI3K (Fig. 1c). No significant effect on cell survival, cell number, protein content or cell morphology was observed due to miltefosine treatment $(40 \mu \mathrm{mol} / 1$ for $60 \mathrm{~min})$ (data not shown). Therefore, for further experiments we decided to pretreat cells with $40 \mu \mathrm{mol} / 1$ for $60 \mathrm{~min}$.

Interaction of insulin with the insulin receptor (IR) leads to tyrosine phosphorylation of IR itself and phosphorylation of a number of proteins downstream such as IRS, PI3K, Akt/PKB, mitogen activated protein kinase (MAPK), glycogen synthase kinase $3 \beta$ (GSK-3 $\beta$ ), c-Jun N-terminal kinase (JNK) etc., which regulate insulin signalling $[6,9$, 10]. Inhibition of PI3K by wortmannin or LY294002 causes inhibition of insulin signalling and glucose uptake [6]. Akt deficiency in mice is associated with insulin resistance, which strongly supports the notion that $\mathrm{Akt} / \mathrm{PKB}$ is important in insulin action [6].

The ability of miltefosine to completely inhibit the phosphorylation and activation of Akt/PKB as well as PI3K, which are central mediators of many insulin effects, led us to hypothesise that miltefosine has inhibitory effect(s) on insulin-stimulated glucose uptake and/or insulin signalling. We examined the effect of miltefosine on 2-DOG uptake. When L6E9 myotubes were pretreated with miltefosine, insulinstimulated 2-DOG uptake (55\%) was inhibited down to the basal level (Fig. 2a). Miltefosine alone had no effect on L6E9 skeletal muscle cells in terms of glucose uptake (Fig. 2a). Inhibition of insulin-stimulated glucose uptake in skeletal muscle contributes to the development of insulin resistance $[6,8]$. Insulin signalling is initiated by the recruitment of intracellular molecules to the activated IR- $\beta$ due to its tyrosine phosphorylation, which activates a number of cellular responses $[6,8]$. When L6E9 cells were pretreated with miltefosine, insulin-stimulated tyrosine phosphorylation of IR- $\beta$ (3.25-fold) was inhibited (Fig. 2b). No effect on IR- $\beta$ tyrosine phosphorylation was observed when the cells were treated with miltefosine alone (Fig. 2b). IRS-1 is a key regulator, downstream from IR- $\beta$ in the insulin-signalling cascade, and is phosphorylated on multiple tyrosine residues $[6,8]$. When L6E9 cells were pretreated with miltefosine, insulin-stimulated tyrosine phosphorylation of IRS-1 (1.92-fold) was inhibited down to the basal level (Fig. 2c). No effect on IRS-1 tyrosine phosphorylation was observed when the cells were treated with miltefosine alone (Fig. 2c). Mice lacking the IRS-1 protein have been reported to be insulin resistant [6].

MAPKs are known to regulate insulin signalling [9]. It is known that the activity of JNK is abnormally elevated in various tissues under diabetic conditions and that activation of the JNK pathway interferes with insulin action [10]. Therefore, we investigated the effect of miltefosine on the activation of MAPKs such as p38, JNK and extracellular signal-regulated kinase (ERK). Results showed that miltefosine activated p38 and JNK1/2, as well as c-Jun (a JNK1 substrate), by five- to sevenfold irrespective of insulin treatment (Fig. 2d-f), although no change in the activation of ERK was detected (data not shown).

GSK-3 $\beta$, a serine/threonine kinase, negatively regulates insulin signalling and an elevated level of GSK-3 $\beta$ has been reported in skeletal muscle in diabetic rodents and humans [6]. Inhibition of Ser9/Ser21 phosphorylation activates GSK-3 $\alpha / \beta$ [6]. The insulin-stimulated increase in Ser9/21 phosphorylation of GSK-3 $\alpha / \beta$ (6.7-fold) was inhibited to basal level when cells were pretreated with miltefosine (Fig. 2g). Miltefosine alone had no effect on GSK- $3 \alpha / \beta$ activation (Fig. $2 \mathrm{~g}$ ). This inhibition of insulinstimulated Ser9/Ser21 phosphorylation of GSK $-3 \alpha / \beta$ by miltefosine might also have contributed in the generation of the insulin-resistant phenotype of L6E9 cells.

In conclusion, we have demonstrated that miltefosine inhibits insulin signalling in L6E9 skeletal muscle cells through IR- $\beta$, IRS-1, PI3K and Akt/PKB pathways, inhibits insulin-stimulated glucose uptake, and ultimately leads to a condition of insulin resistance. Leishmaniainfected patients are treated with miltefosine for 4 weeks at a dosage of $100 \mathrm{mg} /$ day [3]. At this dosage of miltefosine treatment, on day 23 the plasma level of miltefosine was found to be nearly $70 \mu \mathrm{g} / \mathrm{ml}$ (mean value, the range being 40-100 $\mu \mathrm{g} / \mathrm{ml}$ ) (personal communication, G. Anders, Clinical Research, Zentaris, Frankfurt/Main, Germany). However, in our experimental conditions in vitro, miltefosine concentrations up to about $16 \mu \mathrm{g} / \mathrm{ml}(40 \mu \mathrm{mol} / \mathrm{l})$ for $1 \mathrm{~h}$ caused inhibition of insulin-stimulated effects by inhibiting insulin-signalling proteins and glucose uptake. 
Thus, there is a possibility of negatively affecting insulin signalling, either temporarily or permanently, when patients are treated with miltefosine. To the best of our knowledge, there are no reports in the public domain that suggest whether clinical studies on the possibility of miltefosine-mediated type II diabetes tests have been undertaken. Our study in the mouse skeletal muscle cell line is limited by the fact that it cannot be directly translated to human muscle in vivo. However, the defects of insulin signalling by miltefosine described in this study needs further attention and should be addressed in future experimental animal and clinical studies.

Acknowledgements We thank P. R. Rao, Director, NIPER, for his constant encouragement of our work. We are thankful to K. G. Jayanarayan, G. Singh, T. K. Oberoi and B. Bisht for their constant support. R. Singh is acknowledged for technical assistance.

Duality of interest None of the authors has a conflict of interest to declare in connection with this research.

\section{References}

1. Verma NK, Dey CS (2004) Possible mechanism of miltefosine mediated death of Leishmania donovani. Antimicrob Agents Chemother 48:3010-3016

2. Terwogt JMM, Mandjes IAM, Sindermann H, Beijnen JH, ten Bokkel Huinink WW (1999) Phase II trial of topically applied miltefosine solution in patients with skin-metastasized breast cancer Br J Cancer 79:1158-1161

3. Thakur BB (2003) Breakthrough in the management of visceral leishmaniasis. J Assoc Physicians India 51:649-651

4. Desjeux P (2004) Leishmaniasis. Nat Rev Microbiol 2:692-693

5. Ruiter GA, Zerp SF, Bartelink H, Blitterswijk WJV, Verheij M (2003) Anti-cancer alkyl-lysophospholipids inhibit the phosphatidylinositol 3-kinase-Akt/PKB/PKB survival pathway. Anti-Cancer Drugs 14:167-173

6. Zhang BB (2002) Insulin signaling and action: glucose, lipids, protein. http://www.endotext.org/diabetes/diabetes4/diabetesfrme4. $\mathrm{htm}$. Last accessed December 2005

7. Khurana A, Dey CS (2002) Involvement of ELK-1 in L6L9 skeletal muscle cell differentiation. FEBS Lett 527:119-124

8. Kumar N, Dey CS (2003) Metformin enhances insulin signaling in insulin-dependent and -independent pathways in insulin resistant muscle cells. Br J Pharmacol 137:329-336

9. Cusi K, Maezono K, Osman A et al (2000) Insulin resistance differentially affects the PI3-kinase and MAP kinase-mediated signaling in human muscle. J Clin Invest 105:311-320

10. Manning AM, Davis R (2003) Targeting JNK for therapeutic benefit: from junk to gold? Nat Rev Drug Discov 2:554-565 